\title{
Mycobacterium haemophilum osteomyelitis: case report and review of the literature Sameer Elsayed* and Ron Read
}

\author{
Address: 9-3535 Research Rd NW, Calgary, Alberta, Canada T2L 2K8 \\ Email: Sameer Elsayed* - sameer.elsayed@cls.ab.ca; Ron Read - Ron.Read@Calgaryhealthregion.ca \\ * Corresponding author
}

Published: 10 April 2006

BMC Infectious Diseases2006, 6:70 doi:10.1 186/147/-2334-6-70

This article is available from: http://www.biomedcentral.com/I47|-2334/6/70

(C) 2006Elsayed and Read; licensee BioMed Central Ltd.

This is an Open Access article distributed under the terms of the Creative Commons Attribution License (http://creativecommons.org/licenses/by/2.0), which permits unrestricted use, distribution, and reproduction in any medium, provided the original work is properly cited.
Received: 19 December 2005

Accepted: 10 April 2006

\begin{abstract}
Background: Mycobacterium haemophilum is a slow-growing, fastidious, iron-requiring microorganism that, relative to other non-tuberculous mycobacterial species, has rarely been documented as a cause of human infection. This microorganism appears to be acquired via environmental exposure although its natural habitat and mode of acquisition are unknown. It has primarily been implicated as a cause of ulcerating cutaneous or subcutaneous nodular skin lesions, particularly in immunocompromised patients, although infections at extracutaneous sites have also been described. Osteomyelitis, while rarely documented, appears to be an important complication of infection with $M$. haemophilum in these patients.
\end{abstract}

Case presentation: We describe a unique case of culture-confirmed M. haemophilum osteomyelitis in an adult woman with polycythemia vera and review the world literature on bone infections due to this organism.

Conclusion: Mycobacterium haemophilum is an important but infrequently encountered cause of osteomyelitis in immunocompromised patients, often requiring months to years of medical therapy, with or without surgery, to effect a clinical cure.

\section{Background}

Mycobacterium haemophilum is a slow-growing, fastidious, iron-requiring microorganism that, relative to other nontuberculous mycobacterial species, has rarely been documented as a cause of human infection. This microorganism appears to be acquired from environmental exposure although its natural habitat and mode of acquisition are unknown. It has primarily been implicated as a cause of ulcerating cutaneous or subcutaneous nodular skin lesions, particularly in immunocompromised patients, although infections at extracutaneous sites have also been described. Like other nontuberculous mycobacteria, $M$. haemophilum can cause chronic cervicofacial lymphadenitis, particularly in immunocompetent children [1-3].
Osteomyelitis, while rarely documented, appears to be an important complication of infection with $M$. haemophilum in these patients. We report a case of $M$. haemophilum osteomyelitis in a patient with polycythemia vera and provide a summary review of the world literature on $M$. haemophilum bone infections.

\section{Case presentation}

A 56-year-old businesswoman with a 16-year history of polycythemia vera, apparently well controlled with busulfan, presented for medical attention with a 1-month history of painful ulcerating nodular skin lesions on her right wrist and right ankle. The lesions were biopsied, with Ziehl-Neelsen stains demonstrating the presence of acid- 
fast bacilli (AFB). She had lived in Canada for most of her adult life aside from yearly, extended vacations in Arizona, USA. She was not aware of any contact with tuberculous individuals, and had no history of exposure to fish tanks. She recalled experiencing minor trauma to her right wrist just prior to the emergence of the nodular lesions. A Mantoux test was not performed. Physical examination revealed tender nodular and erythematous ankle and wrist lesions ( $3 \mathrm{~cm}$ and $1 \mathrm{~cm}$ in diameter, respectively), with full thickness skin ulceration. Chest X-ray was normal. While awaiting culture results, she was started on clarithromycin $500 \mathrm{mg}$ orally twice daily, ciprofloxacin $500 \mathrm{mg}$ orally twice daily, and rifabutin $300 \mathrm{mg}$ orally once daily, after which her wrist lesion slowly healed. The ankle lesion did not respond significantly to medical therapy. X-rays demonstrated osteolysis of the distal tibia consistent with osteomyelitis. She developed gastrointestinal intolerance to ciprofloxacin and rifabutin, and was continued on clarithromycin alone. At this time, her polycythemia treatment was subsequently switched from busulfan to hydroxyurea. The wrist and ankle bone biopsy specimens were inoculated onto plain and hemin-supplemented Middlebrook 7H10 agar media and BACTEC 12B blood culture bottles incubated at $30^{\circ} \mathrm{C}$ in an aerobic atmosphere (National Mycobacteriology Laboratory, Edmonton, Canada). After 1 and 6 weeks, respectively, growth of acid-fast bacilli was observed only on the hemin-supplemented Middlebrook slants inoculated with the wrist and ankle specimens and definitively identified as $M$. haemophilum by high-performance liquid chromatography (Laboratoire de sante publique du Quebec, Montreal, Canada). Susceptibility testing was performed using Etest (AB BIODISK, Solna, Sweden) on Mueller-Hinton agar supplemented with sheep blood. The organism was susceptible to clarithromycin (MIC $\leq$ $16 \mu \mathrm{g} / \mathrm{ml}$ ) and rifabutin (MIC $\leq 0.12 \mu \mathrm{g} / \mathrm{ml}$ ) but resistant to ciprofloxacin (MIC $4 \mu \mathrm{g} / \mathrm{ml}$ ), amikacin (MIC $\geq 8 \mu \mathrm{g}$ / $\mathrm{ml}$ ), and ethambutol (MIC $\geq 8 \mu \mathrm{g} / \mathrm{ml}$ ) based on unofficial breakpoints proposed by the National Mycobacteriology Laboratory, Edmonton, Canada. Re-biopsy of the ankle lesion demonstrated the presence of AFB but no evidence of superinfection with other pathogens. An HIV test was ordered at this time but was negative. An MRI scan 6 months later demonstrated a significant soft tissue inflammatory mass underlying the ulcer with extension through the cortex of the tibia and into the marrow cavity. After debridement, the ulcer began to granulate and heal over. After one year of follow-up, our patient's ankle lesion had completely epithelialized, aside from the development of a small intermittently draining sinus. Repeat MRI another 6 months later demonstrated resolution of the original soft tissue inflammatory mass but without evidence of bony healing. She improved after 2 years of clarithromycin therapy, with plans to continue therapy indefinitely until there was radiologic evidence of bony healing, although she eventually died of transformation to acute leukemia.

\section{Discussion}

Mycobacterium haemophilum is a slow-growing, fastidious, nontuberculous mycobacterial species that was first isolated and described by Sompolinsky in 1978, who recovered the organism from chronic ulcerating subcutaneous lesions in a woman with Hodgkin's disease [4]. Since then, approximately 100 cases of infection have been described worldwide, with the majority of affected individuals being immunocompromised by virtue of organ or bone marrow transplantation, haematological malignancy, or advanced HIV infection/AIDS [2,5-12]. In such individuals, the classical clinical presentation has been that of multiple tender ulcerating cutaneous or subcutaneous nodular skin lesions, commonly on the extremities and often overlying joints [2,5-12]. Occasionally, lesions have been associated with cellulitis or complicated by abscess formation, fistula development, osteomyelitis, septic arthritis, or bacteremia [2,5-7,9-11]. Cases of pneumonia, pulmonary nodules, or sinusitis without skin lesions have also been described in both immunocompromised and immunocompetent individuals [2,3,5-7,912]. Several cases of localized lymphadenitis, particularly of the cervical, submandibular, and perihilar regions, have been reported in immunocompetent patients, especially children [1-3].

The natural habitat and mode of acquisition of M. haemophilum are unknown. However, the geographic distribution of M. haemophilum is thought to be ubiquitous $[2,9]$. Evidence from reported cases points to an environmental reservoir, possibly aquatic, although attempts to recover the organism through environmental sampling have been unsuccessful $[2,13]$. A few patients have reported antecedent trauma at the site of infection $[11,13]$. Although the pathophysiology of $M$. haemophilum infection is not well understood, cell-mediated immunity appears to play a key role in disease pathogenesis and outcome $[10,11]$.

In common with most other nontuberculous mycobacterial infections, disease is usually chronic [2]. The organism is difficult to cultivate in the laboratory, and is unique among the mycobacteria in its requirement for iron-containing compounds in growth media [2]. Furthermore, $M$. haemophilum requires low incubation temperatures (30$32^{\circ} \mathrm{C}$ ) for growth [2]. Hence, cases of infection due to $M$. haemophilum are likely under-reported. However, advances in molecular biology have greatly facilitated our understanding of the clinical spectrum of infection caused by this microorganism and have paved the way for sensitive and specific detection of $M$. haemophilum directly from clinical specimens or for definitive characterization of suspect clinical isolates using tools such as PCR, real- 
Table I: Summary of reported cases of $M$. haemophilum osteomyelitis in the world literature.

\begin{tabular}{|c|c|c|c|c|c|c|}
\hline Country (Year) & Age/Sex & $\begin{array}{l}\text { Underlying } \\
\text { Disease(s) }\end{array}$ & Anatomic site & Therapy (duration) & Outcome & Reference(s) \\
\hline Australia (1979) & $58 / M$ & Lymphoma & foot & INH, RIF, ETH (N/A) & Partial response & {$[22]$} \\
\hline Australia (1979) & $55 / F$ & Renal transplant & ankle & INH, RIF, ETH (N/A) & Died & [22] \\
\hline Australia (1990) & $39 / M$ & $\begin{array}{l}\text { AIDS, Hodgkin's } \\
\text { disease }\end{array}$ & foot & $\begin{array}{l}\text { AK, CIP, DOX, RIF (I0 } \\
\text { weeks) }\end{array}$ & Cure & {$[6,25]$} \\
\hline Brazil (2000) & $30 / M$ & AIDS & elbow & N/A & N/A & [9] \\
\hline France (1982) & $48 / M$ & Renal transplant & finger & $\begin{array}{l}\text { Surgery; MIN, ERY (> } 2 \\
\text { months) }\end{array}$ & Cure & {$[27]$} \\
\hline France (1984) & $48 / M$ & Renal transplant & ankle & RIF, MIN (N/A) & Cure & {$[2,7,27]$} \\
\hline France (1992) & N/A & AIDS & $\begin{array}{l}\text { fingers, toes, tibia, } \\
\text { elbow, thoracic } \\
\text { vertebrae }\end{array}$ & INH, RIF, ETH (N/A) & No improve-ment & {$[6,32]$} \\
\hline Germany (2002) & $53 / \mathrm{F}$ & AIDS & tibia & ETH, RIF, CLR & Cure & [33] \\
\hline USA (I983) & $\mathrm{N} / \mathrm{A}$ & Cardiac transplant & $\begin{array}{l}\text { wrist, lower } \\
\text { extremity }\end{array}$ & No treatment & $\begin{array}{l}\text { Death from } \\
\text { chronic graft } \\
\text { rejection }\end{array}$ & {$[2,5,17]$} \\
\hline USA (I 984) & $30 / F$ & $\begin{array}{l}\text { Renal transplant } \\
\text { AIDS }\end{array}$ & hand & INH, RIF, ETH, MIN (N/A) & Died & {$[2]$} \\
\hline USA (1990) & $37 M$ & AIDS & ankle & $\begin{array}{l}\text { RIF, ETH. CIP, AK, DOX (I4 } \\
\text { months) }\end{array}$ & Cure & {$[6,7,10,26,28]$} \\
\hline USA (1990) & $38 / M$ & AIDS & N/A & AK, CIP, EMB, RIF (N/A) & Resolved & {$[7,11]$} \\
\hline USA (1990) & $49 / M$ & AIDS & tibia & $\begin{array}{l}\text { INH, RIF, ETH, CIP, CLO, } \\
\text { AK (N/A) }\end{array}$ & Died & [6] \\
\hline USA (1990) & $77 / M$ & T-cell lymphoma & hand & Surgery (curettage only) & $\begin{array}{l}\text { Relapse; Died } \\
\text { from lymphoma } \\
\text { complica-tions }\end{array}$ & [2] \\
\hline USA (I991) & $32 / F$ & AIDS & N/A & CLR, MIN, RIF (N/A) & $\begin{array}{l}\text { Improved; } \\
\text { responded then } \\
\text { relapsed }\end{array}$ & {$[7,11]$} \\
\hline USA (I99I) & $32 / F$ & AIDS & arm & CIP, INH, RIF, PZA (N/A) & Resolution & {$[\mathrm{II}]$} \\
\hline USA (I99I) & $30 / M$ & AIDS & $\mathrm{N} / \mathrm{A}$ & $\begin{array}{l}\text { AK, CLR, CLO, ETH, INH, } \\
\text { RIF (N/A) }\end{array}$ & $\begin{array}{l}\text { Responded then } \\
\text { relapsed }\end{array}$ & {$[7,11]$} \\
\hline USA (I99I) & $5 I / M$ & AIDS & N/A & $\begin{array}{l}\text { CIP, DOX, ETH, INH, PZA, } \\
\text { RIF (N/A) }\end{array}$ & Resolved & {$[7,11]$} \\
\hline USA (I991) & $37 / M$ & AIDS & $N / A$ & $\mathrm{AK}, \mathrm{DOX}(\mathrm{N} / \mathrm{A})$ & Died & {$[\mathrm{II}]$} \\
\hline USA (1992) & $44 / M$ & AIDS & tibia; fibula & $\begin{array}{l}\text { AK, CIP, CLO, ETH, INH, } \\
\text { RIF (N/A) }\end{array}$ & $\begin{array}{l}\text { Responded then } \\
\text { relapsed }\end{array}$ & {$[6,7,18]$} \\
\hline USA (1992) & $30 / F$ & AIDS & $\begin{array}{l}3^{\text {rd }} \text { finger; } \\
\text { calcaneous }\end{array}$ & $\begin{array}{l}\text { RIF, CIP, DOX, AK (I7 } \\
\text { months) }\end{array}$ & Cure & {$[6,26]$} \\
\hline USA (1992) & $21 / F$ & AIDS & tibia & MIN, RIF (N/A) & Responded & {$[2,6,19]$} \\
\hline USA (1993) & $29 / \mathrm{F}$ & AML, BMT & N/A & CIP, CLR, RB (6 months) & Cure & {$[2,10,12]$} \\
\hline USA (1993) & $33 / M$ & AIDS & lower extremity & ETH, CLR, CIP, AK (N/A) & $\begin{array}{l}\text { Died of AIDS } \\
\text { complica-tions }\end{array}$ & [2] \\
\hline USA (1994) & $35 / M$ & AIDS & $\mathrm{N} / \mathrm{A}$ & CIP, CLR, RYF (5 months) & Unknown & {$[10]$} \\
\hline USA (1994) & $4 I / M$ & AIDS & olecranon & RIF, INH, PYZ (N/A) & $\begin{array}{l}\text { Resolved in } 9 \\
\text { months }\end{array}$ & {$[6,24]$} \\
\hline USA (I996) & $46 / M$ & AIDS & foot & CIP, RB, CYC, AZI & $\begin{array}{l}\text { Improved after } \\
\text { treatment }\end{array}$ & {$[20]$} \\
\hline USA (I997) & $20 / M$ & Cardiac transplant & olecranon & CLR, RIF (N/A) & Cure & {$[5,23]$} \\
\hline USA (1998) & $36 / M$ & AIDS & femur & $N / A$ & $N / A$ & {$[21]$} \\
\hline USA (2000) & $47 / \mathrm{F}$ & $\mathrm{AA}, \mathrm{BMT}$ & $\mathrm{N} / \mathrm{A}$ & $\begin{array}{l}\text { CIP, CLR, DOX, RYF (> } 6 \\
\text { months) }\end{array}$ & Improved & {$[10]$} \\
\hline USA (I993) & $33 / M$ & AIDS & lower extremity & ETH, CLR, CIP, AK (N/A) & $\begin{array}{l}\text { Died of AIDS } \\
\text { complica-tions }\end{array}$ & [2] \\
\hline
\end{tabular}

AA, Aplastic anemia; AIDS, acquired immunodeficiency syndrome; AK, amikacin; AML, acute myelocytic leukemia; AZI, azithromycin; BMT, bone marrow transplant; CIP, ciprofloxacin; CLO, clofazamine; CLR, clarithromycin; CYC, cycloserine; DOX, doxycycline; ETH, ethambutol; INH, isoniazid; MIN, minocycline; PYZ, pyrazinamide; RB, rifabutin; RIF, rifampin; RYF, rifamycin (rifampin or rifabutin). N/A = information not available. 
time PCR, or $16 \mathrm{~S}$ ribosomal RNA gene sequencing $[1,14,15]$.

Mycobacterium haemophilum appears to be the most important cause of non-tuberculous mycobacterial osteomyelitis infections in humans [6,16-26]. Over 30 cases of $M$. haemophilum bone infections have been described to date, with most occurring in patients with advanced HIV disease or bone marrow/solid organ transplants (Table 1) [2,5-7,9-12,17-28]. Infections may involve multiple sites, are frequently associated with septic arthritis and/or overlying cutaneous infection, and usually involve the bones of the foot, ankle, knee, elbow, and fingers [2,5-7,9-12,1728]. These and other sites may be involved via contiguous spread or hematogenous dissemination from a pulmonary or cutaneous source. Affected patients may or may not report a history of antecedent trauma. Infections of bone typically develop over the course of several weeks. Plain film radiographs and MRI scans often reveal wellmarginated osteolysis, cortical bone destruction, and adjacent soft tissue inflammation [21]. In a 3-year review of atypical mycobacterial skeletal infections in 25 HIVinfected patients, M. haemophilum accounted for 44\% (11/ 25 ) of cases, followed by infection with $M$. kansasi and $M$. avium-intracellulare [6]. A study from January 1989 to September 1991 at seven metropolitan hospitals in New York City identified 13 patients with culture-confirmed M. haemophilum infections (11 with HIV infection and 2 with bone marrow transplants), of which 6 had osteomyelitis [11]. While our case may be the first report of $M$. haemophilum osteomyelitis in a patient with polycythemia vera, our patient's predisposition to infection was likely a result of myelosuppression from long-term busulfan/hydroxyurea therapy. A case of fatal disseminated non-M. haemophilum atypical mycobacterial infection was reported in a woman with pulmonary fibrosis secondary to long-term busulfan use [29].

Most strains of $M$. haemophilum demonstrate in-vitro susceptibility to ciprofloxacin, clarithromycin, rifamycins, and clofazimine $[2,7,8,12,30]$. Isolates are usually resistant to isoniazid, ethambutol, and pyrazinamide, while susceptibility to doxycycline, minocycline, amikacin, and para-aminosalcylic acid is variable $[2,7,8,12,30]$. There is no consensus on the optimal modality or duration of treatment of $M$. haemophilum bone infections. However, successful treatment of osteomyelitis may require several months of antimicrobial therapy but should be guided by the patient's underlying condition and clinical response. Based on information from previously reported cases, combinations of drugs, including ciprofloxacin, clarithromycin, and/or rifabutin appear to be associated with the greatest potential success when used for the treatment of osteomyelitis or localized skin and soft tissue infection $[2,5-7,10-12,20,31]$. Patients should be monitored peri- odically while on combinations of rifamycins and macrolides due to the potential for drug-drug interactions. Rifabutin induces hepatic cytochrome P-450 enzymes, which may result in increased metabolism of clarithromycin, leading to potentially subtherapeutic concentrations of the latter drug. However, clarithromycin inhibits the hepatic cytochrome P-450 enzymatic pathway, leading to potentially toxic concentrations of rifabutin [23,31]. Rifamycins should not be used alone due to the potential for rapid development of resistance. Patients with localized disease usually respond favorably to medical treatment, although deaths have been reported, especially for disseminated infection $[2,7,8,10,12]$. It has been observed that improvement of immune function during the course of disease may lead to an improve outcome [9] but this has not been well documented in osteomyelitis cases. Surgery has occasionally been used, often in combination with antimicrobial agents, for the treatment of $M$. haemophilum bone infections but the impact of surgery on patient outcome is unknown.

\section{Conclusion}

M. haemophilum is a clinically significant mycobacterial species with a predilection for causing bone infection in immunocompromised individuals. In the appropriate clinical setting, M. haemophilum osteomyelitis should be considered in the differential diagnosis of immunocompromised patient presenting with nodular or ulcerative skin lesions in conjunction radiographic evidence of adjacent bone destruction, especially if tissue biopsies reveal the presence of AFB. Successful outcomes usually require months or even years of medical therapy.

\section{Competing interests}

The author(s) declare that they have no competing interests.

\section{Authors' contributions}

RR was directly involved in the patient's care. SE was the laboratory physician involved in the patient's care. SE performed the literature review. Both authors wrote the manuscript.

\section{Acknowledgements}

While the patient was alive, informed verbal consent was obtained to publish this report.

\section{References}

I. Samra Z, Kaufmann L, Zeharia A, Ashkenazi S, Amir J, Bahar J, Reischl $U$, Naumann L: Optimal detection and identification of Mycobacterium haemophilum in specimens from pediatric patients with cervical lymphadenopathy. J Clin Microbiol I999, 37(3):832-834.

2. Saubolle MA, Kiehn TE, White MH, Rudinsky MF, Armstrong D: Mycobacterium haemophilum: microbiology and expanding clinical and geographic spectra of disease in humans. Clin Microbiol Rev 1996, 9(4):435-447. 
3. White DA, Kiehn TE, Bondoc AY, Massarella SA: Pulmonary nodule due to Mycobacterium haemophilum in an immunocompetent host. Am J Respir Crit Care Med 1999, I60(4): 1366-1368.

4. Sompolinsky D, Lagziel A, Naveh D, Yankilewitz T: Mycobacterium haemophilum sp. nov., a new pathogen of humans. Int J Syst Bacteriol 1978, 28(I):67-75.

5. Fairhurst RM, Kubak BM, Pegues DA, Moriguchi JD, Han KF, Haley JC Kobashigawa JA: Mycobacterium haemophilum infections in heart transplant recipients: case report and review of the literature. Am J Transplant 2002, 2(5):476-479.

6. Hirsch R, Miller SM, Kazi S, Cate TR, Reveille JD: Human immunodeficiency virus-associated atypical mycobacterial skeletal infections. Semin Arthritis Rheum 1996, 25(5):347-356.

7. Kiehn TE, White M: Mycobacterium haemophilum: an emerging pathogen. Eur J Clin Microbiol Infect Dis 1994, I 3(I I):925-93I.

8. Malouf MA, Glanville AR: The spectrum of mycobacterial infection after lung transplantation. Am J Respir Crit Care Med 1999, I60(5 Pt I): $161 \mathrm{I}-1616$

9. Sampaio JL, Alves VA, Leao SC, De Magalhaes VD, Martino MD, Mendes CM, Misiara AC, Miyashiro K, Pasternak J, Rodrigues E, Rozenbaum R, Filho CA, Teixeira SR, Xavier AC, Figueiredo MS, Leite JP: Mycobacterium haemophilum: emerging or underdiagnosed in Brazil? Emerg Infect Dis 2002, 8(I I): I359-I360.

10. Shah MK, Sebti A, Kiehn TE, Massarella SA, Sepkowitz KA: Mycobacterium haemophilum in immunocompromised patients. Clin Infect Dis 200I, 33(3):330-337.

II. Straus WL, Ostroff SM, Jernigan DB, Kiehn TE, Sordillo EM, Armstrong D, Boone N, Schneider N, Kilburn JO, Silcox VA, LaBombardi V, Good RC: Clinical and epidemiologic characteristics of Mycobacterium haemophilum, an emerging pathogen in immunocompromised patients. Ann Intern Med 1994, I 20(2): I I8-125

12. White MH, Papadopoulos EB, Small TN, Kiehn TE, Armstrong D: Mycobacterium haemophilum infections in bone marrow transplant recipients. Transplantation 1995, 60(9):957-960.

13. Smith S, Taylor GD, Fanning EA: Chronic cutaneous Mycobacterium haemophilum infection acquired from coral injury. Clin Infect Dis 2003, 37(7):e100-101.

14. Bruijnesteijn Van Coppenraet ES, Lindeboom JA, Prins JM, Peeters MF, Claas EC, Kuijper E): Real-time PCR assay using fine-needle aspirates and tissue biopsy specimens for rapid diagnosis of mycobacterial lymphadenitis in children. J Clin Microbiol 2004, 42(6):2644-2650.

15. Bruijnesteijn van Coppenraet LE, Kuijper EJ, Lindeboom JA, Prins JM, Claas EC: Mycobacterium haemophilum and lymphadenitis in children. Emerg Infect Dis 2005, I I (I):62-68.

16. Meier JL: Mycobacterial and fungal infections of bone and joints. Curr Opin Rheumatol 1994, 6(4):408-4I4.

17. Cooper DK, Lanza RP, Oliver S, Forder AA, Rose AG, Uys CJ, Novitzky D, Barnard CN: Infectious complications after heart transplantation. Thorax 1983, 38(I I):822-828.

18. Dever LL, Martin JW, Seaworth B, Jorgensen JH: Varied presentations and responses to treatment of infections caused by Mycobacterium haemophilum in patients with AIDS. Clin Infect Dis 1992, 14(6): I 195-1200.

19. Gupta I, Kocher J, Miller AJ, Weisholtz SJ, Perz J, Scully M: Mycobacterium haemophilum osteomyelitis in an AIDS patient. $\mathrm{NJ}$ Med 1992, 89(3):201-202

20. Holladay KL, Carmichael JK: Mycobacterium haemophilum cellulitis and osteomyelitis in a man with AIDS. J Am Board Fam Pract 1996, 9(2): 122-124.

21. Lefkowitz RA, Singson RD: Considering Mycobacterium haemophilum in the differential diagnosis for lytic bone lesions in AIDS patients who present with ulcerating skin lesions. Skeletal Radiol 1998, 27(6):334-336.

22. Mezo A, Jennis F, McCarthy SW, Dawson DJ: Unusual mycobacteria in 5 cases of opportunistic infections. Pathology 1979, I I(3):377-384.

23. Plemmons RM, McAllister CK, Garces MC, Ward RL: Osteomyelitis due to Mycobacterium haemophilum in a cardiac transplant patient: case report and analysis of interactions among clarithromycin, rifampin, and cyclosporine. Clin Infect Dis 1997, 24(5):995-997.

24. Soubani AO, al-Marri M, Forlenza S: Successful treatment of disseminated Mycobacterium haemophilum infection in a patient with AIDS. Clin Infect Dis 1994, I 8(3):475-476.
25. Sowden D, Kemp R, Dawson D: Osteomyelitis due to Mycobacterium haemophilum in a patient with AIDS. Pathology 1993 , 25(3):308-309.

26. Yarrish RL, Shay W, LaBombardi VJ, Meyerson M, Miller DK, Larone D: Osteomyelitis caused by Mycobacterium haemophilum: successful therapy in two patients with AIDS. AIDS 1992, 6(6):557-56I.

27. Gouby A, Branger B, Oules R, Ramuz M: Two cases of Mycobacterium haemophilum infection in a renal-dialysis unit. J Med Microbiol 1988, 25(4):299-300.

28. Kiehn TE, White M, Pursell KJ, Boone N, Tsivitis M, Brown AE, Polsky $B$, Armstrong D: A cluster of four cases of Mycobacterium haemophilum infection. Eur J Clin Microbiol Infect Dis 1993, I2(2): I I4-II8.

29. Watanabe K, Sueishi K, Tanaka K, Nagata N, Hirose N, Shigematsu $\mathrm{N}$, Miake S, Yoshida M: Pulmonary alveolar proteinosis and disseminated atypical mycobacteriosis in a patient with busulfan lung. Acta Pathol Jpn 1990, 40(I):63-66

30. Bernard EM, Edwards FF, Kiehn TE, Brown ST, Armstrong D: Activities of antimicrobial agents against clinical isolates of Mycobacterium haemophilum. Antimicrob Agents Chemother 1993, 37(I I):2323-2326.

31. Griffith DE, Wallace RJ Jr: New developments in the treatment of nontuberculous mycobacterial (NTM) disease. Semin Respir Infect 1996, II(4):30I-3IO.

32. Sabbagh M, Meyer O, De Bandt M, Salomon-Ceron D, Perronne $C$ Rosenbaum W, Tremoliere F, Kahn MF: Bone manifestations associated with acquired immunodeficiency syndrome (AIDS). Ann Med Interne (Paris) 1992, I43(I):50-56.

33. Gruschke A, Enzensberger R, Brade V: [Osteomyelitis of the tibial head caused by Mycobacterium haemophilium in a patient with AIDS]. Dtsch Med Wochenschr 2002, I27(38): 1947-1950.

\section{Pre-publication history}

The pre-publication history for this paper can be accessed here:

http://www.biomedcentral.com/1471-2334/6/70/prepub
Publish with Biomed Central and every scientist can read your work free of charge

"BioMed Central will be the most significant development for disseminating the results of biomedical research in our lifetime. "

Sir Paul Nurse, Cancer Research UK

Your research papers will be:

- available free of charge to the entire biomedical community

- peer reviewed and published immediately upon acceptance

- cited in PubMed and archived on PubMed Central

- yours - you keep the copyright

Submit your manuscript here:

http://www.biomedcentral.com/info/publishing_adv.asp
BioMedcentral 